\title{
Treatment with a Monoclonal Anti-IL-12p40 Antibody Induces Substantial Gut Microbiota Changes in an Experimental Colitis Model
}

\author{
Josué Castro-Mejía, ${ }^{1}$ Maja Jakesevic, ${ }^{2}$ Lukasz Krych, ${ }^{1}$ Dennis S. Nielsen, ${ }^{1}$ Lars H. Hansen, ${ }^{3}$ \\ Bodil C. Sondergaard, ${ }^{4}$ Peter H. Kvist, ${ }^{4}$ Axel K. Hansen, ${ }^{2}$ and Thomas L. Holm ${ }^{4}$ \\ ${ }^{1}$ Department of Food Science, Faculty of Science, University of Copenhagen, Rolighedsvej 26, 1958 Frederiksberg, Denmark \\ ${ }^{2}$ Department of Veterinary Disease Biology, Faculty of Health and Medical Science, University of Copenhagen, Thorvaldsensvej 57, \\ 1870 Frederiksberg, Denmark \\ ${ }^{3}$ Department of Environmental Science, Aarhus University, Frederiksborgvej 399, 4000 Roskilde, Denmark \\ ${ }^{4}$ Novo Nordisk Park, 2760 Maaloev, Denmark
}

Correspondence should be addressed to Thomas L. Holm; thlh@novonordisk.com

Received 24 September 2015; Accepted 30 November 2015

Academic Editor: Jinsheng Yu

\begin{abstract}
Copyright ( 2016 Josué Castro-Mejía et al. This is an open access article distributed under the Creative Commons Attribution License, which permits unrestricted use, distribution, and reproduction in any medium, provided the original work is properly cited.
\end{abstract}

\begin{abstract}
Background and Aim. Crohn's disease is associated with gut microbiota (GM) dysbiosis. Treatment with the anti-IL-12p40 monoclonal antibody (12p40-mAb) has therapeutic effect in Crohn's disease patients. This study addresses whether a 12p40-mAb treatment influences gut microbiota (GM) composition in mice with adoptive transfer colitis (AdTr-colitis). Methods. AdTr-colitis mice were treated with $12 \mathrm{p} 40$ - $\mathrm{mAb}$ or rat-IgG2a or $\mathrm{NaCl}$ from days 21 to 47 . Disease was monitored by changes in body weight, stool, endoscopic and histopathology scores, immunohistochemistry, and colonic cytokine/chemokine profiles. GM was characterized through DGGE and 16S rRNA gene-amplicon high-throughput sequencing. Results. Following 12p40-mAb treatment, most clinical and pathological parameters associated with colitis were either reduced or absent. GM was shifted towards a higher Firmicutesto-Bacteroidetes ratio compared to rat-IgG2a treated mice. Significant correlations between 17 bacterial genera and biological markers were found. The relative abundances of the RF32 order (Alphaproteobacteria) and Akkermansia muciniphila were positively correlated with damaged histopathology and colonic inflammation. Conclusions. Shifts in GM distribution were observed with clinical response to $12 \mathrm{p} 40-\mathrm{mAb}$ treatment, whereas specific GM members correlated with colitis symptoms. Our study implicates that specific changes in GM may be connected with positive clinical outcomes and suggests preventing or correcting GM dysbiosis as a treatment goal in inflammatory bowel disease.
\end{abstract}

\section{Introduction}

Inflammatory bowel disease (IBD) arises from a loss of tolerance and excessive immune response to commensal bacteria in a genetically susceptible host, although environmental factors may influence as well. Ulcerative colitis (UC) and Crohn's disease (CD) are the major forms of IBD affecting the gastrointestinal tract [1]. Key clinical features of these diseases include abdominal pain, weight loss, and diarrhea, which can be hemorrhagic [1-3]. As many as 1.4 million in the United
States and 2.2 million persons in Europe suffer from IBD and the numbers are increasing [4].

Animal models are widely used to study and explain the pathological mechanisms of gut inflammation. In order to study IBD and evaluate anti-inflammatory strategies, a variety of animal models have been developed and are traditionally divided into those with spontaneous development of colitis due to genetic manipulation (e.g., targeted deletion of the anti-inflammatory cytokine IL-10), chemically induced colitis (e.g., dextran sulfate sodium (DSS)), hapten-induced 
colitis (e.g., 2,4,6-trinitrobenzene sulfonic acid (TNBS)), and adoptive transfer (AdTr) models (transfer of $\mathrm{T}$ cells from a donor mouse to a $\mathrm{T}$ cell deficient mouse) [5]. Compared to chemically inducible models of colitis such as those based upon DSS and TNBS, AdTr of $\mathrm{CD} 4^{+} \mathrm{CD} 25^{-} \mathrm{T}$ cells into immune deficient mice more closely reflects the altered gene expression in human IBD [6]. Mouse models of colitis induced by AdTr of $\mathrm{CD} 25^{-}$depleted $\mathrm{CD} 4^{+} \mathrm{T}$ cells are highly suitable for pharmacological testing of new IBD drug candidates because they are easy and fast to perform (compared to other chronic models, e.g., SAMP-1/Yit) [7, 8], there is no generation of anti-drug antibodies, and it results in uniform and highly reproducible clinical and pathological signs of colitis [9]. Three weeks after adoptive cell transfer most recipient mice develop clear signs of colitis, characterized by weight loss, loose stools, increased white blood cell (WBC) count, and thickened and shortened colon [5].

Anti-IL-12/23p40 monoclonal antibody (mAb) targets the $\mathrm{p} 40$ subunit common to IL-12. IL-12 is formed by two chains, IL-12p35 and IL-12p40, which together form the active heteromer IL-12p70 [10], whereas the active heterodimer IL23 is formed by IL-12p40 and IL-12p19. Both IL-12 and IL23 are produced by monocytes, macrophages, and dendritic cells in response to microbial stimulation [10]. IL-12 induces the generation of $\mathrm{T}$ helper cells type $1\left(\mathrm{~T}_{\mathrm{H}} 1\right)$ [11], and it enhances the cytotoxic activities of natural killer (NK) cells [12] leading to secretion of several cytokines, especially interferon-gamma (IFN- $\gamma$ ) [11]. IL-23 stimulates CD $4^{+}$T cells to differentiate into a novel subset of $\mathrm{T}$ helper cells called $\mathrm{T}_{\mathrm{H}} 17$ cells. $\mathrm{T}_{\mathrm{H}} 17$ cells produce proinflammatory cytokines that enhance $\mathrm{T}$ cell priming and stimulate the production of other proinflammatory molecules such as IL-1, IL-6, and TNF- $\alpha$, as well as chemokines resulting in inflammation [1315]. $\mathrm{CD}$ has been associated with excess cytokine activity mediated by $\mathrm{T}_{\mathrm{H}} 1$ and $\mathrm{T}_{\mathrm{H}} 17$ cells. IL- 12 and IL- 23 are increased in patients with $\mathrm{CD}$, but their production is downregulated after administration of IL-12/23p40 monoclonal antibody [7, $13,16,17]$. Clinical trials with anti-IL12/23p40 therapy have shown encouraging results in $\mathrm{CD}$ patients not responding to the first-line biologic treatment, which is anti-TNF- $\alpha \mathrm{mAb}$. The reason why anti-IL12/23p40 works particularly well in this patient segment is currently unknown, but it could be due to specific genetic alterations, as well as microbiota/gut interactions common in the IL-12/23p40 pathway driving the pathogenesis in these patients. Moreover, alterations in gut microbiota (GM) have been shown as a predictor of relapse in CD patients [18].

Genetically engineered animal models of IBD do not develop fulminant colitis under germ-free conditions, but gut inflammation evolves when they are colonized by bacteria, which points out the important role of the GM in the initiation and development of colitis [19, 20]. Moreover, antibiotics may ameliorate experimental colitis even in a therapeutic setting [7]. Several studies have shown that IBD is accompanied by a shift in GM towards higher abundance of proinflammatory bacteria, such as Enterobacteriaceae, while the abundance of, for example, lactobacilli and bifidobacteria is reduced [21-24]. Furthermore, a number of studies indicate that GM diversity is reduced in colitis $[21,25,26]$.
However, detailed knowledge on how GM composition changes in relation to colitis is still limited and more studies are required to verify the alternations in the overall composition of GM during intestinal inflammation and to which extent such alternations are of importance in a preventive or therapeutic intervention. Identifying relevant links between GM composition and clinical parameters of colitis is also of great importance.

Consequently, the aim of the present study was to evaluate how microbiota composition in colonic content correlated with clinical signs of IBD in mice treated with monoclonal anti-IL12/23p40 antibody (12p40-mAb) in an adoptive T cell transfer model of colitis (AdTr-colitis).

\section{Materials and Methods}

2.1. Mice. All experiments were conducted in accordance with the European Communities Council Directive 86/609/ ECC for the protection of animals used for experimental purposes, approved by the Danish Animal Experiments Inspectorate, Ministry of Food, Fisheries and Agriculture, Denmark, and the internal Ethical Review Council at Novo Nordisk A/S.

C.B-Igh-1b/IcrTac-Prkdcscid (C.B-17 SCID) and BALB/ cAnNTac female mice (8-10 weeks) bred under barrier protected conditions (Taconic, Ll. Skensved, Denmark) were housed at Novo Nordisk A/S. Mice were identified using Plexx microchips (Plexx, Elst, Netherlands) and were randomized in the cages to reduce cage effects. Dirty cage bedding was transferred to the individual cages before the experiment was initiated as well as once weekly during the experiment. Health monitoring was performed according to FELASA guidelines [27].

2.2. Purification of Cells and Induction of Colitis. Colitis was induced by AdTr of CD $4^{+} \mathrm{CD} 25^{-} \mathrm{T}$ cells (AdTr-colitis) from spleen of MHC-compatible BALB/c mice to C.B-17 SCID recipients as previously described [9]. Briefly, splenocytes of $\mathrm{BALB} / \mathrm{c}$ donor mice were subjected for positive selection of $\mathrm{CD}^{+} \mathrm{T}$ cells using Dynabeads and DETACHaBEAD (Life Technologies Europe, Ballerup, Denmark) and depletion of $\mathrm{CD}_{25}{ }^{+}$from the $\mathrm{CD} 4{ }^{+} \mathrm{T}$ cell suspensions using the CD25 MicroBead kit. Flow cytometry was used to analyze purity of the cells and showed that more than $98 \%$ of the $\mathrm{CD}^{+}$ cells were CD $25^{-}$cells. Each recipient was reconstituted with 300,000 cells by intraperitoneal injection. Two or three weeks after transfer, peripheral blood from all mice was analyzed by flow cytometry for the presence of $\mathrm{CD} 4{ }^{+} \mathrm{T}$ cells. Only animals with successful transplantation of cells were included in the study.

2.3. Experimental Groups. The mice were divided into four groups. One group of nontreated C.B-17 SCID mice (SCID control) were not subjected to AdTr-colitis $(n=4)$, while the three groups of adoptively transferred C.B-17 SCID mice were treated with a neutralizing rat anti-mouse IL-12/23p40 monoclonal antibody (12p40-mAb) (clone C17.8) $(n=15)$ or rat-IgG2a monoclonal isotype antibody (clone 2A3) $(n=13)$ or $\mathrm{NaCl}(n=14)$ from day 21 until termination at day 47. 
The antibodies were purchased from Bio X Cell (New Hampshire, USA) and had been tested for endotoxins. The antibodies were injected intraperitoneally three times weekly and dosed according to body weight at $25 \mathrm{mg} \mathrm{kg}^{-1}$.

2.4. Monitoring of Disease. Animals were weighed three times per week and mice that lost more than $20 \%$ of the initial weight were sacrificed. Fecal samples were evaluated and scored from 0 to 4 according to their consistency (normal stool $=0$; slightly soft stool $=1$; soft but formed stool $=2$; not formed stool $=3$; liquid stools or no feces in the colon at sacrifice $=4)$. Disease activity index score $(\mathrm{DAI})$ was calculated based on data obtained from weight loss and feces type as previously described by Murthy et al. [28]. As fecal blood is rarely observed in AdTr-colitis it was not monitored. Mice were anaesthetized by isoflurane (Isoba Vet, MSD Animal Health, Ballerup, Denmark) and blood was obtained by retroorbital puncture. All blood samples were collected in EDTA K2 coated microtubes (Milian, Gahanna, Ohio, USA). EDTAstabilized peripheral whole blood samples $(20 \mu \mathrm{L})$ were used for monitoring the number of white blood cells (WBC) per liter with Medonic CA 620 (Boule Nordic, Denmark) blood analysis apparatus according to the manufacturer's protocol. Colonoscopy was performed on days 21 and 34 . Mice were anaesthetized with isoflurane and placed in dorsal recumbency. A rigid telescope (HOPKINS Straight Forward, $0^{\circ}$ ) was connected to a light source/air pump (Xenon 175) and camera (Telecam SL) as described by Becker et al. [29] The endoscope $(2 \mathrm{~mm})$ was coated with a lubricant containing lidocaine hydrochloride (Farco-Pharma, Köln, Germany) and introduced via the anus into the distal $4 \mathrm{~cm}$ of the colon. The evaluation of the colonoscopic findings was done by two blinded observers using the murine endoscopic index of colitis severity (MEICS) score (Supplemental Table 1 in Supplementary Material available online at http://dx.doi.org/10 $.1155 / 2016 / 4953120$ ), as outlined by Becker et al. [30].

2.5. Postmortem Analysis. Mice were sacrificed by cervical dislocation on day 47. However, one mouse in the rat-IgG2a group was sacrificed at day 45 due to severe weight loss. After the animals were sacrificed the colon was excised and opened longitudinally. Fecal and colonic content was collected in a sterile Eppendorf tube and tissue was gently rinsed with saline and its weight $(W, \mathrm{mg})$ and length $(L, \mathrm{~cm})$ were measured. The left halves of colon were used for cytokine measurements and the right halves were fixed on a plastic plate with pins and processed for histological analysis. Cecum was excised and its contents were collected in sterile Eppendorf tubes.

2.6. Histology. Tissue for histology was fixed in $4 \%$ paraformaldehyde (VWR-Bie \& Berntsen, Herlev, Denmark) for approximately 24 hours at $4^{\circ} \mathrm{C}$. Subsequently, the samples were transferred to $70 \%$ ethanol and stored at $4{ }^{\circ} \mathrm{C}$ until processed for histopathology. The samples were processed in a Leica Asp300S histoprocessor (Leica Microsystems, Ballerup, Denmark) overnight, embedded in paraffin blocks using a Shandon Histocentre 3 (Thermo Electron Corporation, Marietta, Ohio), and sectioned at a thickness of $3 \mu \mathrm{m}$ in a Leica Microtome RM 2165 (Leica Microsystems, Ballerup, Denmark). Subsequently, the slides were stained with hematoxylin (Ampliqon, Skovlunde, Denmark) and eosin (SigmaAldrich, Brøndby, Denmark) (H\&E) for light-microscopic examination, Olympus Ax70 microscope. The severity of the histopathological lesions of colon segments was examined in a blinded manner, using the criteria described in Supplemental Table 2.

For immunohistochemical (IHC) detection of $\mathrm{CD} 3$ or S100A8 (calprotectin) paraformaldehyde fixed colon sections were mounted on adhesive slides (Superfrost Plus, MenzelGläser, Germany) dried at $60^{\circ} \mathrm{C}$ and kept at $4^{\circ} \mathrm{C}$ until processed. Tissue sections were processed through xylene and rehydrated. For CD3 IHC the tissue sections were boiled in Tris-EGTA buffer and quenched with $\mathrm{H}_{2} \mathrm{O}_{2}(0,5 \%)$. Tissue sections were blocked (with goat and mouse serum, BSA, and skim milk) and slides were incubated with polyclonal rabbit anti-human CD3 antibody (RM-9107-S; SP7, Thermo Scientific). After washing in TBS buffer secondary antibodypolymer complex (Envision, K4003) was applied. Then, slides were developed with diaminobenzidine (DAB) and counterstained in Meyer's hematoxylin and mounted with Pertex.

For calprotectin IHC staining the tissue sections were boiled in citrate buffer and quenched with $\mathrm{H}_{2} \mathrm{O}_{2}(0,5 \%)$. Endogenous biotin was blocked using an avidin-biotin blocking kit. Nonspecific binding was blocked by incubation with TBS containing skimmed milk, donkey serum, and mouse serum. The primary antibody (Rat-a-Mo S100A8 (MRP-8), MyBiosource) and secondary antibody (Biotin-SP Donkey Anti-Rat IgG, Jackson ImmunoResearch) were diluted in Tris-buffer containing skimmed milk and donkey and mouse sera and incubated for $60 \mathrm{~min}$ each at room temperature. Next, an amplification step was performed by incubation with Vectastain $\mathrm{ABC}$ Peroxidase Kit for $30 \mathrm{~min}$ followed by a chromogenic reaction with DAB. Nuclei were counterstained with Meyer's hematoxylin and the sections were rehydrated, cleared in xylene, and mounted with Pertex. Control immunostainings were run without the primary antibody and with a nonsense polyclonal antibody of the same concentration as the primary antibody for both CD3 and calprotectin.

Automated digital image analyses were performed on the IHC positive areas using the Visiopharm Integrator System (VIS, version 4.5.1.324, Visiopharm, Hørsholm, Denmark). On individual digital images of the proximal and distal colon sections, a region-of-interest (ROI) was automatically defined of both colon sections using $K$-means clustering classification. Subsequently, an analysis was run using threshold classification inside the ROI to detect the brown DAB staining of the specific calprotectin IHC immunostaining. The results are given as area stained with $\mathrm{CD} 3$ or calprotectin of the entire colon sections (\%).

2.7. Cytokine Measurements. Tissue for cytokine analysis was weighed and transferred to individual $3.6 \mathrm{~mL}$ CryoTubes containing Tissue Homogenate Lysis Buffer (Ampliqon, Skovlunde, Denmark). The buffer was a solution of $200 \mathrm{mM}$ $\mathrm{NaCl}, 5 \mathrm{mM}$ EDTA, $10 \mathrm{mM}$ Tris, $10 \%$ glycerin, $1 \mathrm{mM}$ PMSF, $1 \mu \mathrm{g} \mathrm{mL}^{-1}$ leupeptin, and $28 \mu \mathrm{g} \mathrm{mL}^{-1}$ aprotinin ( $\mathrm{pH}$ 7.4). 
The buffer was kept cold (approx. $4^{\circ} \mathrm{C}$ ) at all times. The tubes were immediately snap-frozen in liquid nitrogen and stored at $-80^{\circ} \mathrm{C}$ until homogenized. Using an Ultra-Turrax T25 basic disperser (IKA-Werke, Staufen, Germany) the colon segments were homogenized and the homogenates were centrifuged three times for $15 \mathrm{~min}$ at $10,000 \times \mathrm{g}$ and $4^{\circ} \mathrm{C}$, twice in Eppendorf tubes and the last time in an Ultrafree MCCentrifugal Filter device, $5 \mu \mathrm{m}$ pore size (Millipore, Billerica, Massachusetts, USA). The supernatants were analyzed for levels of colonic cytokines and chemokine using Milliplex (Millipore, Billerica, Massachusetts, USA). The assays were run according to the manufacturer's guidelines with the exception that the standard and test samples were diluted in the Tissue Homogenate Lysis Buffer rather than the kitsupplied assay diluents.

2.8. Gut Microbiota Characterization. Cecal, colonic, and fecal contents collected at euthanasia were homogenized three times for $20 \mathrm{sec}$ at speed $5.5 \mathrm{~m} / \mathrm{sec}$ prior to extraction using a Bead Beater (FastPrep-24, MP Biomedicals, Santa Ana, USA). DNA was extracted using the QIAamp DNA Stool Mini Kit (Qiagen, Hilden, Germany) according to the manufacturer's instructions. Concentration and quality of the extracted DNA were measured using a NanoDrop 1000 Spectrophotometer (Thermo Scientific, USA). A preliminary screening of the GM diversity (based on profiles of $16 \mathrm{~S}$ rRNA amplicons) of cecal, colonic, and fecal contents was performed using denaturing gradient gel electrophoresis (DGGE) as outlined in Pyndt Jørgensen et al. [31]. Only DNA extracted from colon contents was subjected to highthroughput sequencing (Illumina MiSeq). The V3-V4 region of the 16S rRNA gene (amplicon size $\sim 460 \mathrm{bp}$ ) was amplified with primers including adapters for the Nextera Index Kit (Illumina, California, USA). The primers sequences, conditions for amplification and tagmentation (1st and 2 nd round of PCR), purification, and sequencing were performed as previously described [31]. Pair-ended reads (with corresponding quality scores) were trimmed and merged using the CLC Genomic Workbench 7.0.4 (CLC bio, Aarhus, Denmark) [31]. The UPARSE algorithm [32] was used for OTU clustering (97\%) and filtering of chimeric sequences, while the GreenGenes database $97 \%$ (version 12.10) was used for OTU picking [33]. The dataset was further analyzed using the Quantitative Insight Into Microbial Ecology (QIIME versions 1.7.0 and 1.8.0) [34].

Relative quantification of Akkermansia muciniphila was carried out as previously described [35]. Briefly, the reaction mixture $(20 \mu \mathrm{L})$ contained $10 \mu \mathrm{L}$ of $1 \mathrm{x}$ SYBR green PCR Master Mix (Applied Biosystems), $1 \mu \mathrm{L}$ of either A. muciniphila specific-primers or $16 \mathrm{~S}$ rRNA universal primers (each primer was used at a final concentration $0.5 \mu \mathrm{M}), 4 \mu \mathrm{L}$ of nucleasefree water, and $5 \mu \mathrm{L}$ of DNA template $\left(20 \mathrm{ng} \mu \mathrm{L}^{-1}\right)$. The temperature profile for qPCR was as follows: $95^{\circ} \mathrm{C}$ for $5 \mathrm{~min}$ and 40 cycles of $95^{\circ} \mathrm{C}$ for $15 \mathrm{~s}$ and $60^{\circ} \mathrm{C}$ for $1 \mathrm{~min}$. For generation of the standard curve, serial tenfold dilutions of A. muciniphila DSMZ 22959 genomic DNA were used.

2.9. Statistical Analyses. General statistical analyses were carried out using GraphPad Prism version 5.01 (GraphPad
Software, La Jolla, California, USA). Unpaired Student's $t$-test was used when comparing the means of normally distributed parametric data from two groups and a Mann-Whitney $U$ test was performed when comparing non-Gaussian distributed data from two groups. When three or more groups with parametric data were compared one-way ANOVA was used with Tukey's posttest. The Kruskal-Wallis with Dunn's posttest was used on multiple datasets that did not assume Gaussian distributions. For high-throughput sequencing, the number of sequences used for subsample ( $-e$ value, Alpha and Beta Diversity; $-d$ value, multiple rarefactions) was set to $90 \%$ of the most indigent sample. The Jackknife Beta Diversity workflow was used to generate PCoA plots (based on 10 distance matrices that were determined using 10 subsampled OTU tables). Differences between categories in UniFrac distance matrices were assessed with analysis of similarities (ANOSIM). Alpha Diversity was measured and expressed as observed species (97\% similarity OTUs) and computed with 10 rarefied OTU tables. Comparison of Alpha Diversities was made through nonparametric $t$-test method (Monte Carlo, 999 permutations). The occurrence and absence of OTUs associated with a given group of mice were assessed with the $G$-test of independence, whereas differences in the abundance of OTUs were tested with ANOVA. Finally, differences in the relative abundance of $A$. muciniphila determined by qPCR were evaluated using two-tailed Student's $t$-test.

\section{Results}

3.1. Monitoring of Disease (DAI Score, Weight Change, and Pathology). The $\mathrm{CD} 4^{+} \mathrm{CD} 25^{-} \mathrm{T}$ cell transfer was well tolerated by the mice, and no adverse events directly related to $12 \mathrm{p} 40-\mathrm{mAb}$, rat-IgG2a isotype control, or $\mathrm{NaCl}$ were detected. Mice were randomized according to body weight (BW) on day 19. No apparent signs of disease were observed within the first two weeks after AdTr-colitis (data not shown). The change in BW over the course of the experiment from days 21 to 47 is shown in Figure 1(a). Mice started to lose weight in the 3 rd- 4 th week following transfer. The weight loss progressed until the termination of the study. Mice treated with 12 p40-mAb did not show any apparent weight loss and were similar to SCID control mice, whereas mice treated with the isotype control and $\mathrm{NaCl}$ developed severe weight loss $(p<0.0001$ and $p<0.0007)$. No significant differences were observed between $\mathrm{NaCl}$ and rat-IgG2a treated groups. The disease activity index (DAI) is a combined index from 0 to 8 containing weight loss (score $0-4$ ) and stool score (score $0-4$ ), which gives an overall evaluation of the disease intensity during the study. DAI was significantly lower in mice treated with $12 \mathrm{p} 40-\mathrm{mAb}$ compared to rat-IgG2a $(p<$ $0.001)$ and $\mathrm{NaCl}(p<0.006)$ (Figure 1(b)). In animal models of AdTr-colitis, disease can be associated with thickening and shortening of the colon wall as a host inflammatory response. As expected, the colon $W: L$ ratio was increased in mice receiving $\mathrm{NaCl}$ and rat-IgG2a. A significant treatment effect was observed with the $12 \mathrm{p} 40-\mathrm{mAb}$ compared to the isotype treated group $(p<0.0002)$ and $\mathrm{NaCl}(p<0.0009)$ (Figure 1(c)), whereas no differences were observed between their controls groups. 


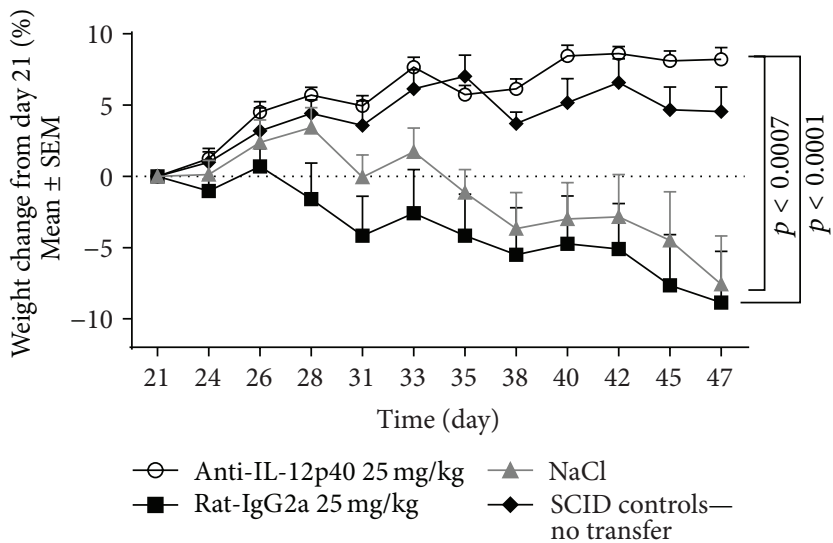

(a)

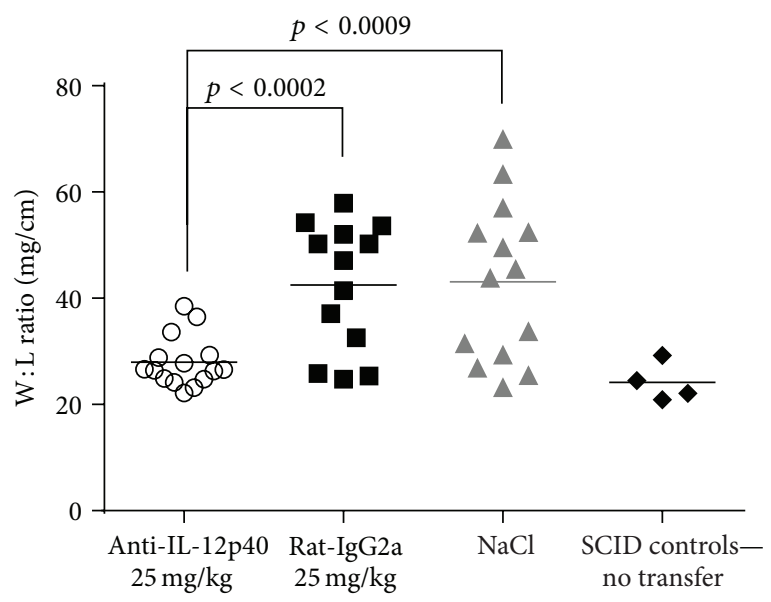

(c)

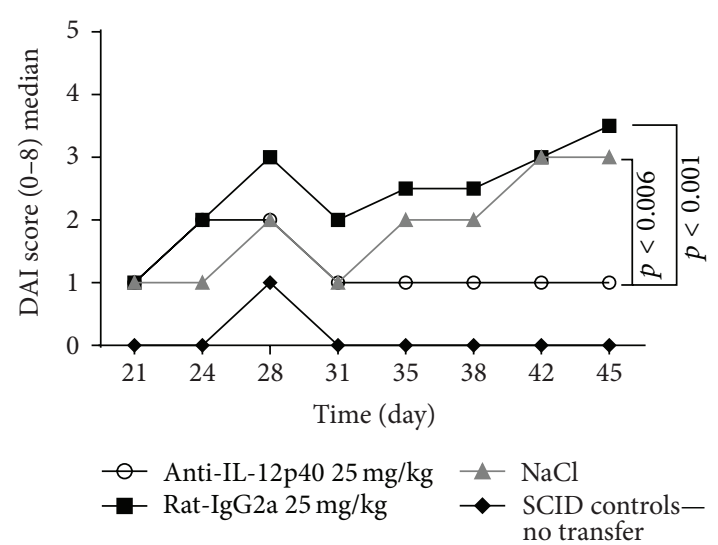

(b)

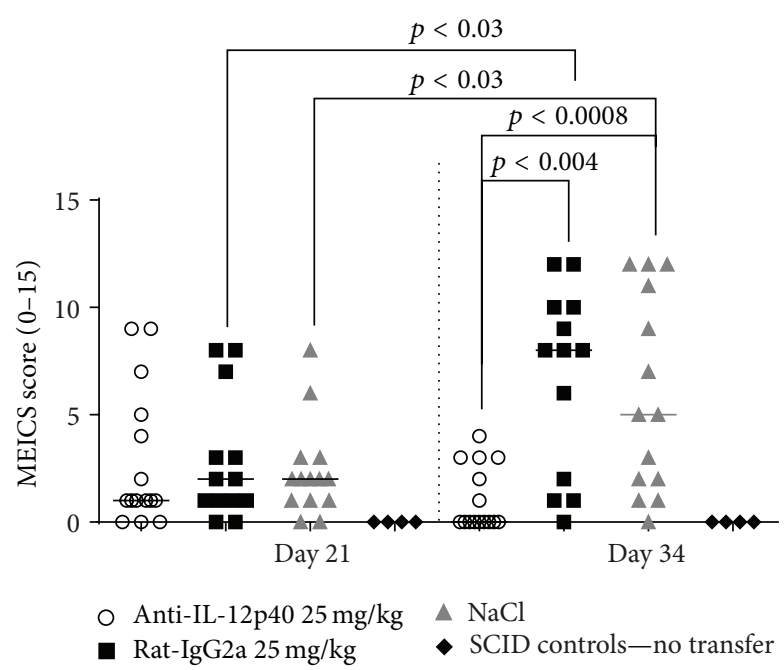

(d)

FIGURE 1: Induction of AdTr-colitis is associated with weight loss, loose stools, and colonic inflammation. (a) Delta weight loss from day 21 is shown as mean \pm SEM for individual groups. Significant differences between the areas under the curve (AUC) for individual mice were determined by Student's $t$-test. (b) DAI was determined with a combined scale from 0 to 8 by combining weight loss ( $0-4)$ and stool score $(0-4)$. Differences in DAI scores were calculated as AUC for individual mice from 21 to 45 days using Mann-Whitney $U$ test. (c) The colon weight- $(\mathrm{mg})$ to-length $(\mathrm{cm})$ ratio was calculated for individual mice. Comparisons between groups were performed using Student's $t$-test. (d) Endoscopic analysis of colon at 21 and 34 days was graded with MEICS. All mice were scored semiquantitatively in a blinded fashion. Significant differences were determined with Mann-Whitney $U$ test for unpaired analysis and Wilcoxon for paired analysis.

Endoscopic pictures were acquired for monitoring and grading inflammation using MEICS (encompassing the thickening of the colon, changes of vascular pattern, visible fibrin, granularity of mucosal surface, and stool consistency). After randomization but prior to treatment (day 21), the majority of mice had clear signs of colonic inflammation; nevertheless, no significant difference between the groups could be detected (Figure 1(d)). At day 34, however, mice treated with the $12 \mathrm{p} 40$-mAb had a significant reduction in the endoscopic score, compared to mice treated with rat-IgG2a $(p<0.004)$ and $\mathrm{NaCl}(p<0.0008)$. No differences were observed between the $12 \mathrm{p} 40-\mathrm{mAb}$ treated and healthy SCID control mice. Similarly, no difference was observed between the rat-IgG2a and $\mathrm{NaCl}$ treated mice at day 34 (Figure 1(d)).
When comparing disease progressions within the groups at day 21 versus day 34, mice treated with rat-IgG2a and $\mathrm{NaCl}$ increased their endoscopic score, from day 21 to day 34 (both $p<0.03$ ). In comparison, mice treated with the IL12p40-mAb showed signs of disease amelioration, $p<0.09$ (Figure 1(d)).

3.2. Histopathology and Immunohistochemical Staining. At day 47, a significant reduction in histopathology scores was observed in mice treated with $12 \mathrm{p} 40-\mathrm{mAb}$ compared to the corresponding isotype control $(p<0.0001)$ and $\mathrm{NaCl}(p<$ 0.0008 ) (Figures $2(\mathrm{a})$ and $2(\mathrm{~d})$ ), while no significant differences were observed between the control groups. Since pathogenic CD4 T cells drive disease progression in AdTr-colitis, 


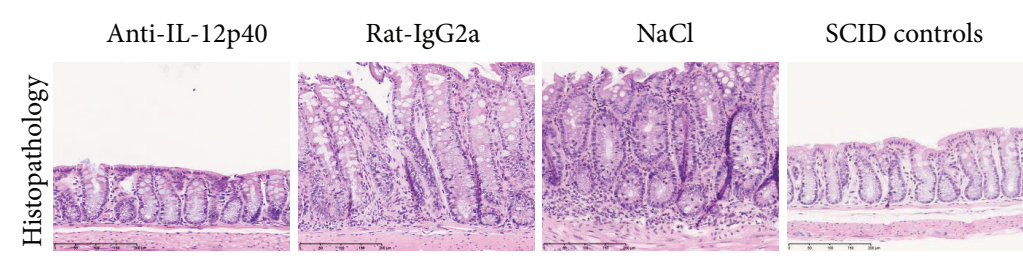

(a)

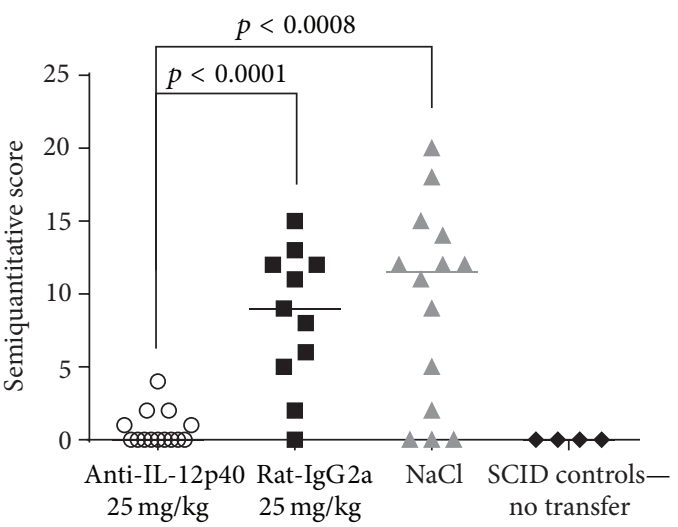

(d)

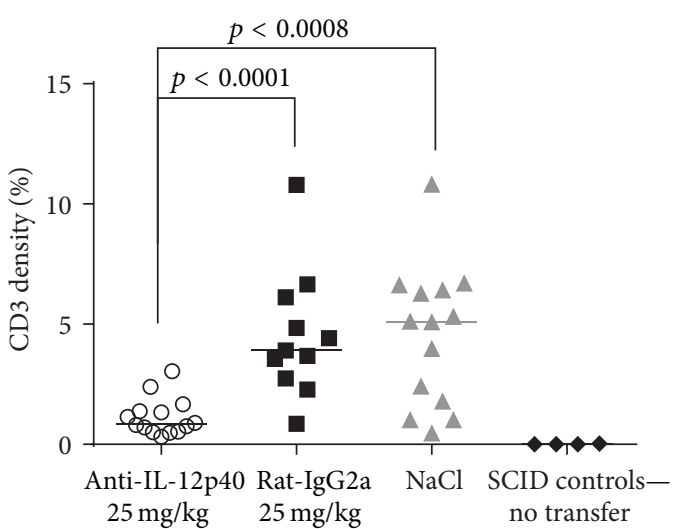

(e)

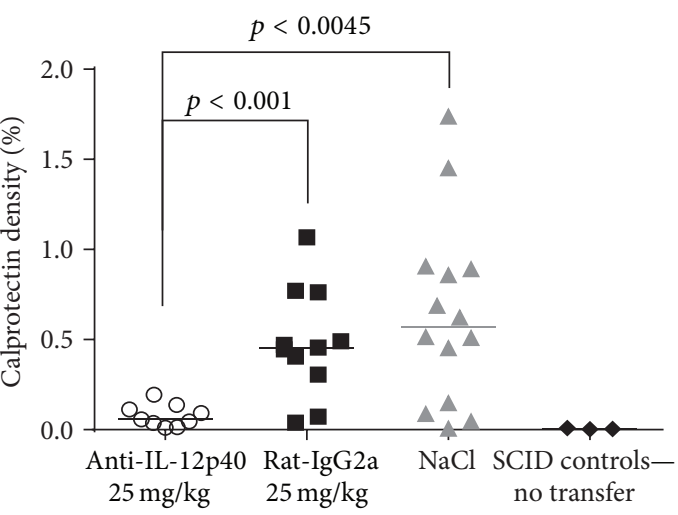

(f)

FIGURE 2: Histology and immunohistochemistry of representative areas of mouse colon. The left panel (a, b, c) shows the histopathological and IHC evaluation of the colon. After H\&E staining (a), the 12p40-mAb treated mice had normal morphology as seen in the SCID control mice. Rat-IgG2a and $\mathrm{NaCl}$ treated mice had major hyperplasia of the mucosal layer and infiltration of immune cells. The CD3 (b) and calprotectin (c) IHC identify these immune cells as being CD3 or calprotectin positive cells as visualized with the brown DAB staining of the positive cells in the mucosa layer and submucosa. The scale bar indicates $200 \mu \mathrm{m}$ and all images are captured at 20x magnification. The images are from the mouse with the results representing the group median for the specific staining of the four mice groups. The right panel (d, e, $\mathrm{f}$ ) depicts the results from the histopathological (d) evaluation using a semiquantitative score (range 0-24). CD3 (e) and calprotectin (f) staining were quantitatively assessed by digital image analysis; data is represented as the density of the IHC reactivity (\%).

colonic sections were stained for a $\mathrm{T}$ cell marker (CD3). The percentage of CD3 stained colon tissue was then used to monitor the effect of $12 \mathrm{p} 40-\mathrm{mAb}$ on colonic T cell inflammation. Mice treated with $12 \mathrm{p} 40$-mAb had significantly lower density of $\mathrm{CD} 3$ as compared to the isotype control and $\mathrm{NaCl}$ $(p<0.0001$ and $p<0.0008$, resp.) (Figures 2(b) and 2(e)). Calprotectin is primarily found in the cytosol of neutrophils and is dramatically upregulated in areas of inflammation, 
TABLE 1: Cytokine and chemokine levels in colon.

\begin{tabular}{|c|c|c|c|c|c|}
\hline \multirow{2}{*}{ pg/100 mg colon ${ }^{\mathrm{A}}$} & \multicolumn{3}{|c|}{ Mice group } & \multirow{2}{*}{$\begin{array}{c}\text { Significance } \\
12 \mathrm{p} 40-\mathrm{mAb} \text { versus rat-IgG2a }\end{array}$} & \multirow{2}{*}{$\begin{array}{c}\text { Significance } \\
12 \mathrm{p} 40-\mathrm{mAb} \text { versus SCID }\end{array}$} \\
\hline & SCID healthy control & $12 \mathrm{p} 40-\mathrm{mAb}$ & rat-IgG2a & & \\
\hline CCL5 & $192 \pm 72$ & $229 \pm 35$ & $493 \pm 62$ & $<0.001$ & 0.600 \\
\hline IL-2 & $182 \pm 24$ & $156 \pm 19$ & $95 \pm 11$ & 0.010 & 0.430 \\
\hline IL-5 & $69 \pm 15$ & $118 \pm 37$ & $31 \pm 3$ & 0.020 & 0.400 \\
\hline IL-9 & $1,489 \pm 180$ & $1,379 \pm 194$ & $683 \pm 97$ & 0.004 & 0.730 \\
\hline IL-10 & $164 \pm 30$ & $156 \pm 22$ & $91 \pm 10$ & 0.010 & 0.840 \\
\hline IL-13 & $932 \pm 145$ & $763 \pm 122$ & $392 \pm 52$ & 0.009 & 0.430 \\
\hline IP-10 & $926 \pm 567$ & $965 \pm 180$ & $3,446 \pm 606$ & $<0.001$ & 0.930 \\
\hline $\mathrm{KC}$ & $224 \pm 44$ & $167.5 \pm 31$ & $440 \pm 61$ & $<0.001$ & 0.310 \\
\hline TNF- $\alpha$ & $28 \pm 5$ & $24 \pm 5$ & $60 \pm 7$ & $<0.001$ & 0.630 \\
\hline
\end{tabular}

${ }^{\mathrm{A}}$ Cytokine and chemokine levels in colon were evaluated by Luminex assay and are depicted as pg per $100 \mathrm{mg}$ colon tissue. Only three of the study groups were included in the analysis (12p40-mAb, rat-IgG2a, and SCID control mice).

whereas it is seldom observed in healthy tissue. Compared to the isotype control and $\mathrm{NaCl}$ treatments, mice treated with $12 \mathrm{p} 40-\mathrm{mAb}$ had lower density of calprotectin (or neutrophil inflammation) in the colon $(p<0.001$ and $p<0.0045$, resp.) (Figures 2(c) and 2(f)). No significant differences were determined between the control groups.

3.3. Cytokines. Total colonic cytokine/chemokine levels were determined in colon biopsies from mice treated with $12 \mathrm{p} 40$ $\mathrm{mAb}$ or rat-IgG2a or healthy controls. Several proinflammatory cytokines and chemokines (TNF- $\alpha$, CCL5, IP-10, and $\mathrm{KC}$ ) were significantly elevated in mice treated with rat-IgG2a compared to $12 \mathrm{p} 40-\mathrm{mAb}$ treated mice (Table 1 ). The cytokine/chemokine levels in $12 \mathrm{p} 40-\mathrm{mAb}$ treated mice were not different from the healthy control mice (Table 1). Moreover, mice treated with $12 \mathrm{p} 40-\mathrm{mAb}$ had significantly higher levels of $\mathrm{T}_{\mathrm{H}} 2$ (IL-5, IL-9, and IL-13) and the immunosuppressive cytokine IL-10 compared to rat-IgG2a treated mice (Table 1). Thus, different $\mathrm{T}$ cell environments may be induced by the two treatment settings.

3.4. Gut Microbiota Composition. Significant changes of $16 \mathrm{~S}$ rRNA amplicons profiles, based on denaturing gradient gel electrophoresis (DGGE), were observed within gut contents of the $\mathrm{NaCl}$ and $12 \mathrm{p} 40-\mathrm{mAb}$ treated mice (Supplemental Figure 1). Since significant differences between the colon contents of $12 \mathrm{p} 40-\mathrm{mAb}$ and rat-IgG2a were also observed, the DNA from colonic contents was subjected to highthroughput sequencing (Illumina MiSeq). The number of reads obtained by sequencing of $16 \mathrm{~S}$ rRNA gene (V3-V4 region) amplicons from 32 colonic fecal samples was 1,697,168 (mean sequence length of $341 \mathrm{bp}$ ). After preprocessing (trimming, quality control, sorting, and chimera filtering), the number of high quality reads obtained was 990,505, whereas the number of sequences per sample varied from 14,534 to 61,423 (average of $30,953 \pm 9,561$ ). The estimated average number of observed OTU-species in the 12p40-mAb treated group $(n=9)$, SCID control $(n=3)$, rat-IgG2a treated group $(n=9)$, and $\mathrm{NaCl}$ group $(n=11)$ was not significantly different [a reduced number of samples were subjected to sequencing due to limited sequencing capacity; samples were randomly selected and all treatments were represented] $(t$ test, $p>0.05$; Supplemental Table 3). Similarly, no differences in Beta Diversity were observed between the 12p40$\mathrm{mAb}$ and SCID control (nonactive disease) or between the isotype and $\mathrm{NaCl}$ treated mice (active colitis) (ANOSIM, $p>0.05$ ). Principal coordinate analysis of weighted UniFrac distance matrices, however, showed significant separation of the nonactive disease and active colitis mice (ANOSIM, $p<0.01$, weighted $r=0.18$; Figure 3). Furthermore, their GM showed changes in the relative abundance of 7 genera (Table 2) [not statistically different after correcting for multiple comparisons] and at the phylum level a significantly lower ( $t$-test, $p>0.05)$ Firmicutes : Bacteroidetes ratio was seen in the colitis active mice (0.30) as compared to the nonactive disease mice (0.83) (however, when only $12 \mathrm{p} 40-\mathrm{mAb}$ and rat-IgG2a were compared no significant differences were observed, putatively due to low number of observations and high intersample variation). Such lower relative abundance of operational taxonomic units (OTUs) assigned to phylum Firmicutes was partially caused by a drop in the relative abundance of Clostridiales from $34.5 \%$ to $15.9 \%$ (constituted by members of Ruminococcus, Oscillospira, and an unclassified genus).

\subsection{Correlation of Gut Microbiota Composition to Disease} Parameters. Seventeen genus-level OTUs correlated either positively or negatively with changes in host parameters (Figure 4 and Supplemental Table 4). Within highly abundant members, Bacteroides (with a range in relative distribution of 1.5-89\%) showed strong positive correlations with most host parameters (with exception of weight AUC) as well as inverse correlations against IL-2, IL-9, and IL-13. Two unclassified genera of Clostridiales (1.2-63\%, unclassified Clostridiales and unclassified Lachnospiraceae), Oscillospira (0.1-8.5\%), and S24-7 family (3-60\%) correlated only negatively with the host parameters, while the latter group correlated positively with IL-2, IL-9, IL-10, and IL-13 (Figure 4). The rest of the OTUs that showed significant correlations did not exceed $15 \%$ of relative distribution.

Upon categorization of host parameters (intervals scores) the prevalence of two OTUs at the genus-level, assigned 
TABLE 2: Changes in taxa abundance between active colitis (rat-IgG2a and $\mathrm{NaCl}$ ) and nonactive disease (12p40-mAb and healthy) determined by ANOVA.

\begin{tabular}{|c|c|c|c|c|c|c|c|c|}
\hline \multirow[b]{2}{*}{ Phylum } & \multirow[b]{2}{*}{ Class } & \multirow[b]{2}{*}{ Order } & \multirow[b]{2}{*}{ Family } & \multirow[b]{2}{*}{ Genus } & \multicolumn{2}{|c|}{ Relative distribution } & \multicolumn{2}{|c|}{ Significance } \\
\hline & & & & & $\begin{array}{l}\text { Active } \\
\text { colitis }\end{array}$ & $\begin{array}{c}\text { Nonactive } \\
\text { disease }\end{array}$ & $p$ value & $q$-value ${ }^{\mathrm{A}}$ \\
\hline Bacteroidetes & Bacteroidia & Bacteroidales & Bacteroidaceae & Bacteroides & $37.19 \%$ & $11.32 \%$ & 0.002 & 0.060 \\
\hline Bacteroidetes & Bacteroidia & Bacteroidales & [Paraprevotellaceae] & Unclassified & $0.14 \%$ & $0.05 \%$ & 0.004 & 0.072 \\
\hline Firmicutes & Clostridia & Clostridiales & Ruminococcaceae & Ruminococcus & $0.47 \%$ & $3.89 \%$ & 0.004 & 0.054 \\
\hline Firmicutes & Clostridia & Clostridiales & Unclassified & Unclassified & $13.22 \%$ & $26.45 \%$ & 0.010 & 0.100 \\
\hline Firmicutes & Clostridia & Clostridiales & Ruminococcaceae & Oscillospira & $2.20 \%$ & $4.21 \%$ & 0.029 & 0.225 \\
\hline Bacteroidetes & Bacteroidia & Bacteroidales & Porphyromonadaceae & Parabacteroides & $0.68 \%$ & $0.15 \%$ & 0.044 & 0.288 \\
\hline TM7 & TM7-3 & CW040 & F16 & Unclassified & $0.01 \%$ & $0.02 \%$ & 0.045 & 0.249 \\
\hline
\end{tabular}

${ }^{\mathrm{A}} q$-values were determined with the False Discovery Rate correction method.

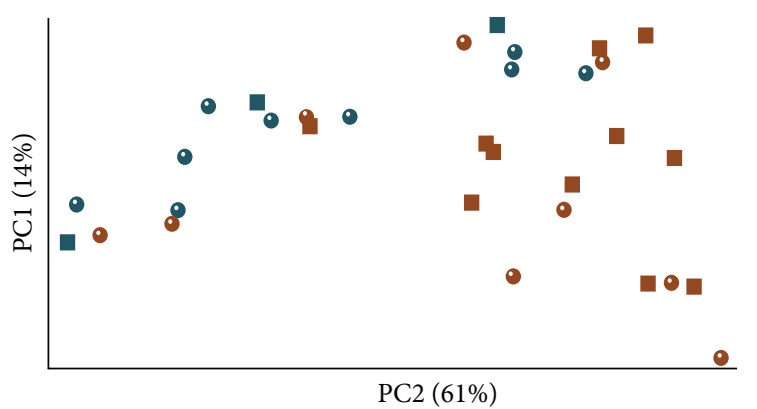

FIGURE 3: Beta Diversity analysis separates nonactive disease [lightblue] (12p40-mAb [circles] and healthy [squares]) from active colitis mice [orange] (rat-IgG2a [circles] and $\mathrm{NaCl}$ [squares]). PCoA plot (unscaled) was determined through weighted UniFrac metrics (ANOSIM, $p<0.01, r=0.18$ ) of the colonic microbiota from 32 mice. The ellipsoids highlight the degree of variation around each sample.

to Akkermansia (relative abundance of $0-7.8 \%$ and $\leq 0.001-$ $11.6 \%$ as determined by Illumina sequencing and speciesspecific qPCR, resp.) and an unclassified member of the RF32 order (0.1 to 9.2\%, Alphaproteobacteria related to Rhodospirillum rubrum), was associated (G-test, $p<0.05)$ with high histopathology scores (Figure 5). Furthermore, species-specific qPCR confirmed that an increase in relative abundance of Akkermansia muciniphila was associated with high scores of the same host parameter (Figure 5). Likewise, the prevalence of both bacteria was significantly associated also with high scores of CD3 density (scores $>2.7$ ), disease AUC (scores $>39.5$ ), and calprotectin (scores $>0.15$ ). Additionally, prevalence of RF32 order was also observed in high scores of colon ratio (>33.7).

\section{Discussion}

Several studies support a causal role of a dysfunctional mucosal barrier in the manifestation of IBD. Recent findings have shed light on the mechanisms by which intestinal epithelial cells, microbiota, and immune cells interact and react in such an environment and how loss of normal regulatory processes may lead to IBD [17-20]. We have focused on the regulation of GM following treatment with a monoclonal antibody against IL-12p40 in an AdTr-colitis mouse model, in which IBD development was clearly prevented by the treatment. Most clinical and pathological signs in treated mice were either clearly reduced or not apparent at all. In other words, mice subjected to both AdTr-colitis and 12p40$\mathrm{mAb}$ treatments appeared similar to SCID control mice, whereas mice treated with the isotype antibody developed severe signs of IBD. Comparable results have been achieved by others in the DSS model [36]. Changes in GM seem to be a shared primary phenomenon in both IBD patients and AdTr-colitis mice, and our results show that treatment with $12 \mathrm{p} 40-\mathrm{mAb}$ restores the GM composition, that is, similar to SCID mice. In addition, the colonic cytokine response with increased levels of IL-5, IL-9, IL-10, and IL-13 clearly shows that it induces a $\mathrm{T}_{\mathrm{H}} 2$ response, which is expectable when IL-12/IL-23 is prevented from inducing a $T_{H} 1 / T_{H} 17$ profile. In contrast to what has been observed in CD patients [37] and the mice treated with the isotype antibody, rodents subjected to the $12 \mathrm{p} 40-\mathrm{mAb}$ treatment had a higher ratio of Firmicutes: Bacteroidetes. Furthermore, in $\mathrm{CD}$ patients a reduction in bacterial diversity as well as lower relative distribution of bacteria with anti-inflammatory properties has been reported [18, 38]. In our study, however, the overall diversity of the GM was not changed by the treatment. Whether dysbiosis or even specific bacterial strains can be future surrogate markers for inflammation, incomplete disease control, relapse, and response remains uncertain. However, caution should be taken when extrapolating from mouse to human. On the other hand, the increased Firmicutes: Bacteroidetes ratio in mice treated with 12p40$\mathrm{mAb}$ was mainly due to the fact that the treated mice had higher proportion of Clostridiales members, many of which correlated inversely to clinical symptoms and TNF- $\alpha$ levels. Clostridium spp. are strong inducers of Foxp3-positive regulatory $\mathrm{T}$ cells in the colonic mucosa of mice [39], and transfer of a mixture of 17 human Clostridium spp. or related bacteria to mice also increased their level of regulatory $\mathrm{T}$ cells [40]. This fits nicely with our observation that $12 \mathrm{p} 40$ $\mathrm{mAb}$ significantly upregulated IL-10 in colon. In our study, 


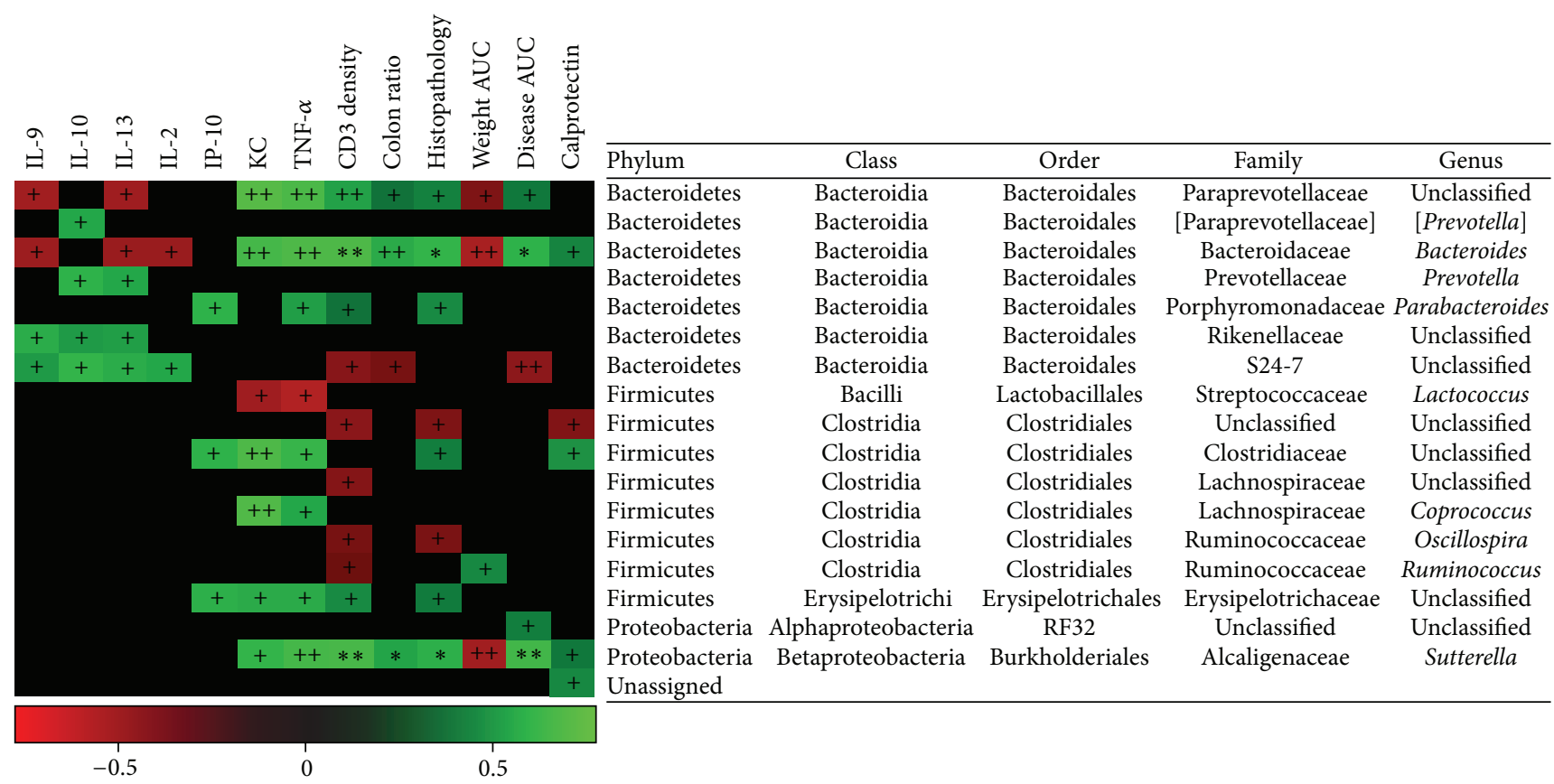

FIgURE 4: Pearson's correlation of immunological and host parameters with changes in the relative distribution of microbiota members of the colonic content. On top of the heat map the immunological and host parameters are depicted. The lineages are marked on the right and are represented by five major taxonomic ranks. Symbols describing significant correlations were defined as follows: for $p$ value, $+\leq 0.05$ and $++\leq$ 0.01 . For $q$-value (False Discovery Rate correction), $* \leq 0.05$ and $* * \leq 0.01$. A matrix containing the $r$-values for every significant correlation is shown in Supplemental Table 4.

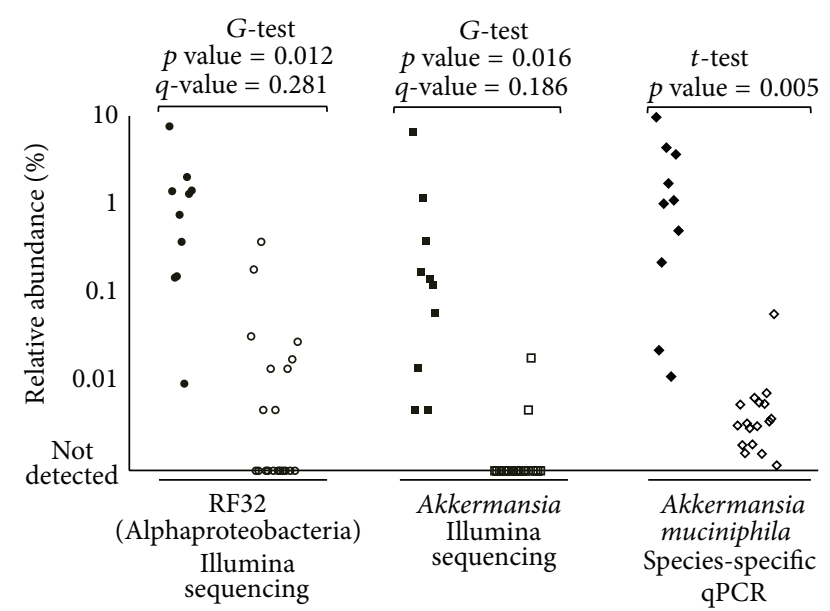

Figure 5: Bacterial prevalence in mice with high and low histopathology scores. Filled marks illustrate scores between 6 and 24, while empty marks illustrate those between 0 and 2. Samples in which RF32 (Alphaproteobacteria), Akkermansia (Illumina sequencing), and A. muciniphila (species-specific qPCR) were detected are represented by their relative distribution. Samples that were negative (no bacteria detected) are depicted at the no detection line. $q$-values were determined with the False Discovery Rate correction method.

an unclassified genus of Clostridiaceae family correlated positively to clinical symptoms, presence of effector cells and proinflammatory cytokines, but this is not necessarily in conflict with the other observations, as there are also a number of Clostridiales families in mice, which are known to induce inflammation [41].

Mice treated with $12 \mathrm{p} 40-\mathrm{mAb}$ had lower relative abundance of Bacteroides, and we observed a positive correlation between the abundance of Bacteroides with clinical symptoms and TNF- $\alpha$ levels. This is in accordance with the fact that both B. vulgatus [42] and B. fragilis [43] are known to induce intestinal inflammation in rodent models. It is of interest to note that the abundance of Prevotella correlates positively with IL-10 levels. In the DSS model they are known to increase severity of IBD [44, 45], but it is difficult to compare the DSS model with the AdTr model in this aspect as only few of the IL-10 producing cells are present in the recipient SCID background, and thus, their IL10 levels will be different at baseline. It is well known that shifts in GM may lead to a change in the $T_{H} 1 / T_{H} 2 / T_{H} 17$ balance, which again may prevent symptoms of $\mathrm{T}_{\mathrm{H}} 1 / \mathrm{T}_{\mathrm{H}} 17$ induced diseases such as CD. It, however, seems to be novel that an anti- $\mathrm{T}_{\mathrm{H}} 1 / \mathrm{T}_{\mathrm{H}} 17$ treatment, such as $12 \mathrm{p} 40-\mathrm{mAb}$, also leads GM towards an anti-inflammatory direction. In our controlled setup, correlations between mice GM members and biological markers were significantly associated, but this is seldom the case in humans [18]. On the other hand some mechanisms seem to be shared despite this lack of heterogeneity.

Surprisingly A. muciniphila correlated with high expression of clinical IBD symptoms as determined by histopathology. A. muciniphila is a mucin-degrader with high mucinase 
activity [46], which accounts for more than $1 \%$ of the bacterial cells in human feces [47]. Extracellular vesicles of A. muciniphila protect against DSS induced IBD in mice [48], and its prevalence is decreased manyfold in patients with either UC or CD [49]. Nevertheless, one possible explanation of our results is that intestinal inflammation may induce higher production of mucin that would primarily be degraded by $A$. muciniphila [50]. In the azoxymethane/DSS model of colon cancer $A$. muciniphila also seems to correlate to an increased number of colon tumors [51]. The prevalence of Alphaproteobacteria was found to be associated with high histopathological scores, they have previously been reported to be highly prevalent in fecal microbiota of UC patients [52], and their role in IBD pathogenesis seems to be associated with proinflammatory changes and GM dysbiosis [53].

\section{Conclusions}

Here we report that $12 \mathrm{p} 40-\mathrm{mAb}$ treatment in an AdTr-colitis mouse model of colitis leads to GM changes and that specific GM composition and members correlate with histopathological changes and cytokine responses. In addition, increasing the proportion of a number of Clostridiales members seems to be associated with prevention and attenuation of colitis symptoms. Thus, our results encourage the search for biomarkers based on GM and prevention or correction of dysbiosis as a potential treatment in IBD.

$\begin{array}{ll}\text { Abbreviations } \\ \text { IBD: } & \text { Inflammatory bowel disease } \\ \text { UC: } & \text { Ulcerative colitis } \\ \text { CD: } & \text { Crohn's disease } \\ \text { 12p40-mAb: } & \text { Rat anti-mouse IL-12/23p40 } \\ & \text { monoclonal antibody } \\ \text { IHC: } & \text { Immunohistochemical } \\ \text { DAI: } & \text { Disease activity index } \\ \text { MEICS: } & \text { Murine endoscopy index of } \\ & \text { colitis severity } \\ \text { GM: } & \text { Gut microbiota } \\ \text { OTU: } & \text { Operational taxonomic unit } \\ \text { SCID: } & \text { Severe combined immunodeficiency } \\ \text { AdTr-colitis: } & \text { Adoptive transfer colitis. }\end{array}$

\section{Conflict of Interests}

Peter Helding Kvist, Bodil C. Søndergaard, and Thomas Lindebo Holm work for Novo Nordisk A/S.

\section{Authors' Contribution}

Josué Castro-Mejía and Maja Jakesevic contributed equally to the study. Josué Castro-Mejía and Maja Jakesevic drafted and wrote part of the paper. Josué Castro-Mejía carried out preparation of sequencing-libraries, qPCR experiments and analyzed the high-throughput sequencing dataset. Bodil C. Søndergaard and Peter H. Kvist performed histology and immunohistochemistry experiments. Maja Jakesevic performed DGGE and collected the microbiome samples.
Łukasz Krych participated in molecular experiments and preprocessing of the high-throughput sequencing data. Lars $\mathrm{H}$. Hansen carried out DNA sequencing and helped to draft the paper. Thomas L. Holm performed the animal study and supported clinical assays including cytokine/chemokine analysis. Dennis S. Nielsen, Axel K. Hansen, and Thomas L. Holm conceived the study and experimental design and drafted and wrote parts of the paper. All authors read the paper, provided critical inputs, and approved the final version of the paper.

\section{Acknowledgments}

The authors like to thank Anders Hansen, Camilla Frost Sørensen, and Lotte Friis for fine technical in vivo assistance and Jeanette Juul for performing fine laboratory work for histology. This work was supported by grants from the University of Copenhagen Excellence Programme for Interdisciplinary Research project "CALM" (Josué Castro-Mejía), Villum Foundation, and the Danish Strategic Research Council project "Neomune" (Łukasz Krych).

\section{References}

[1] R. B. Sartor, "Mechanisms of disease: pathogenesis of Crohn's disease and ulcerative colitis," Nature Clinical Practice Gastroenterology \& Hepatology, vol. 3, no. 7, pp. 390-407, 2006.

[2] D. C. Baumgart and W. J. Sandborn, "Crohn's disease," The Lancet, vol. 380, no. 9853, pp. 1590-1605, 2012.

[3] I. Ordás, L. Eckmann, M. Talamini, D. C. Baumgart, and W. J. Sandborn, "Ulcerative colitis," The Lancet, vol. 380, no. 9853, pp. 1606-1619, 2012.

[4] E. V. Loftus Jr., "Clinical epidemiology of inflammatory bowel disease: incidence, prevalence, and environmental influences," Gastroenterology, vol. 126, no. 6, pp. 1504-1517, 2004.

[5] S. Nell, S. Suerbaum, and C. Josenhans, "The impact of the microbiota on the pathogenesis of IBD: lessons from mouse infection models," Nature Reviews Microbiology, vol. 8, no. 8, pp. 564-577, 2010.

[6] A. A. te Velde, F. De Kort, E. Sterrenburg et al., "Comparative analysis of colonic gene expression of three experimental colitis models mimicking inflammatory bowel disease," Inflammatory Bowel Diseases, vol. 13, no. 3, pp. 325-330, 2007.

[7] T. Lindebo Holm, S. S. Poulsen, H. Markholst, and S. ReedtzRunge, "Pharmacological evaluation of the scid t cell transfer model of colitis: as a model of Crohn's disease," International Journal of Inflammation, vol. 2012, Article ID 412178, 11 pages, 2012.

[8] M. M. Kosiewicz, C. C. Nast, A. Krishnan et al., "Thl-type responses mediate spontaneous ileitis in a novel murine model of Crohn's disease," The Journal of Clinical Investigation, vol. 107, no. 6, pp. 695-702, 2001.

[9] S. Kjellev, D. Lundsgaard, S. S. Poulsen, and H. Markholst, "Reconstitution of Scid mice with $\mathrm{CD} 4{ }^{+} \mathrm{CD} 25^{-} \mathrm{T}$ cells leads to rapid colitis: an improved model for pharmacologic testing," International Immunopharmacology, vol. 6, no. 8, pp. 1341-1354, 2006.

[10] K. R. B. Bastos, C. R. F. Marinho, R. Barboza, M. Russo, J. M. Álvarez, and M. R. D'Império Lima, "What kind of message does IL-12/IL-23 bring to macrophages and dendritic cells?" Microbes and Infection, vol. 6, no. 6, pp. 630-636, 2004. 
[11] R. Manetti, F. Gerosa, M. G. Giudizi et al., "Interleukin 12 induces stable priming for interferon $\gamma$ (IFN- $\gamma$ ) production during differentiation of human $\mathrm{T}$ helper (Th) cells and transient IFN- $\gamma$ production in established Th2 cell clones," The Journal of Experimental Medicine, vol. 179, no. 4, pp. 1273-1283, 1994.

[12] S. H. Chan, M. Kobayashi, D. Santoli, B. Perussia, and G. Trinchier, "Mechanisms of IFN-gamma induction by natural killer cell stimulatory factor (NKSF/IL-12)," The Journal of Immunology, vol. 148, no. 1, pp. 92-98, 1992.

[13] W. J. Sandborn, B. G. Feagan, R. N. Fedorak et al., "A randomized trial of ustekinumab, a human interleukin-12/23 monoclonal antibody, in patients with moderate-to-severe Crohn's disease," Gastroenterology, vol. 135, no. 4, pp. 1130-1141, 2008.

[14] W. J. Sandborn, C. Gasink, L.-L. Gao et al., "Ustekinumab induction and maintenance therapy in refractory Crohn's disease," The New England Journal of Medicine, vol. 367, no. 16, pp. 15191528, 2012.

[15] D. Yen, J. Cheung, H. Scheerens et al., "IL-23 is essential for T cell-mediated colitis and promotes inflammation via IL-17 and IL-6," The Journal of Clinical Investigation, vol. 116, no. 5, pp. 1310-1316, 2006.

[16] P. J. Mannon, I. J. Fuss, L. Mayer et al., "Anti-interleukin-12 antibody for active Crohn's disease," The New England Journal of Medicine, vol. 351, no. 20, pp. 2069-2079, 2004.

[17] I. J. Fuss, C. Becker, Z. Yang et al., "Both IL-12p70 and IL-23 are synthesized during active Crohn's disease and are downregulated by treatment with anti-IL-12 p40 monoclonal antibody," Inflammatory Bowel Diseases, vol. 12, no. 1, pp. 9-15, 2006.

[18] S. Rajca, V. Grondin, E. Louis et al., "Alterations in the intestinal microbiome (Dysbiosis) as a predictor of relapse after infliximab withdrawal in Crohn's disease," Inflammatory Bowel Diseases, vol. 20, no. 6, pp. 978-986, 2014.

[19] R. K. Sellon, S. Tonkonogy, M. Schultz et al., "Resident enteric bacteria are necessary for development of spontaneous colitis and immune system activation in interleukin-10-deficient mice," Infection and Immunity, vol. 66, no. 11, pp. 5224-5231, 1998.

[20] K. L. Madsen, J. S. Doyle, L. D. Jewell, M. M. Tavernini, and R. N. Fedorak, "Lactobacillus species prevents colitis in interleukin 10 gene-deficient mice," Gastroenterology, vol. 116, no. 5, pp. 1107$1114,1999$.

[21] N. A. Nagalingam, J. Y. Kao, and V. B. Young, "Microbial ecology of the murine gut associated with the development of dextran sodium sulfate-induced colitis," Inflammatory Bowel Diseases, vol. 17, no. 4, pp. 917-926, 2011.

[22] S. M. Bloom, V. N. Bijanki, G. M. Nava et al., "Commensal Bacteroides species induce colitis in host-genotype-specific fashion in a mouse model of inflammatory bowel disease," Cell Host and Microbe, vol. 9, no. 5, pp. 390-403, 2011.

[23] M. M. Heimesaat, A. Fischer, B. Siegmund et al., "Shift towards pro-inflammatory intestinal bacteria aggravates acute murine colitis via toll-like receptors 2 and 4," PLoS ONE, vol. 2, no. 7, article e662, 2007.

[24] C. Lupp, M. L. Robertson, M. E. Wickham et al., "Host-mediated inflammation disrupts the intestinal microbiota and promotes the overgrowth of Enterobacteriaceae," Cell Host and Microbe, vol. 2, no. 2, pp. 119-129, 2007.

[25] B. Deplancke, K. Finster, W. V. Graham, C. T. Collier, J. E. Thurmond, and H. R. Gaskins, "Gastrointestinal and microbial responses to sulfate-supplemented drinking water in mice," Experimental Biology and Medicine, vol. 228, no. 4, pp. 424-433, 2003.
[26] S. J. Ott, M. Musfeldt, D. F. Wenderoth et al., "Reduction in diversity of the colonic mucosa associated bacterial microflora in patients with active inflammatory bowel disease," Gut, vol. 53, no. 5, pp. 685-693, 2004.

[27] W. Nicklas, P. Baneux, R. Boot et al., "Recommendations for the health monitoring of rodent and rabbit colonies in breeding and experimental units," Laboratory Animals, vol. 36, no. 1, pp. 2042, 2002.

[28] S. N. S. Murthy, H. S. Cooper, H. Shim, R. S. Shah, S. A. Ibrahim, and D. J. Sedergran, "Treatment of dextran sulfate sodiuminduced murine colitis by intracolonic cyclosporin," Digestive Diseases and Sciences, vol. 38, no. 9, pp. 1722-1734, 1993.

[29] C. Becker, M. C. Fantini, and M. F. Neurath, "High resolution colonoscopy in live mice," Nature Protocols, vol. 1, no. 6, pp. 2900-2904, 2007.

[30] C. Becker, M. C. Fantini, S. Wirtz et al., "In vivo imaging of colitis and colon cancer development in mice using high resolution chromoendoscopy," Gut, vol. 54, no. 7, pp. 950-954, 2005.

[31] B. Pyndt Jørgensen, J. T. Hansen, L. Krych et al., "A possible link between food and mood: dietary impact on gut microbiota and behavior in BALB/c mice," PLoS ONE, vol. 9, no. 8, Article ID e103398, 2014.

[32] R. C. Edgar, "UPARSE: highly accurate OTU sequences from microbial amplicon reads," Nature Methods, vol. 10, no. 10, pp. 996-998, 2013.

[33] D. McDonald, M. N. Price, J. Goodrich et al., "An improved Greengenes taxonomy with explicit ranks for ecological and evolutionary analyses of bacteria and archaea," The ISME Journal, vol. 6, no. 3, pp. 610-618, 2012.

[34] J. G. Caporaso, J. Kuczynski, J. Stombaugh et al., "QIIME allows analysis of high-throughput community sequencing data," Nature Methods, vol. 7, no. 5, pp. 335-336, 2010.

[35] C. H. F. Hansen, T. L. Holm, Ł. Krych et al., "Gut microbiota regulates NKG2D ligand expression on intestinal epithelial cells," European Journal of Immunology, vol. 43, no. 2, pp. 447-457, 2013.

[36] S. Melgar, L. Karlsson, E. Rehnström et al., "Validation of murine dextran sulfate sodium-induced colitis using four therapeutic agents for human inflammatory bowel disease," International Immunopharmacology, vol. 8, no. 6, pp. 836-844, 2008.

[37] H. Sokol, P. Seksik, J. P. Furet et al., "Low counts of faecalibacterium prausnitzii in colitis microbiota," Inflammatory Bowel Diseases, vol. 15, no. 8, pp. 1183-1189, 2009.

[38] H. Sokol, P. Seksik, L. Rigottier-Gois et al., "Specificities of the fecal microbiota in inflammatory bowel disease," Inflammatory Bowel Diseases, vol. 12, no. 2, pp. 106-111, 2006.

[39] K. Atarashi, T. Tanoue, T. Shima et al., "Induction of colonic regulatory T cells by indigenous Clostridium species," Science, vol. 331, no. 6015, pp. 337-341, 2011.

[40] K. Atarashi, T. Tanoue, K. Oshima et al., “Treg induction by a rationally selected mixture of Clostridia strains from the human microbiota," Nature, vol. 500, no. 7461, pp. 232-236, 2013.

[41] J. Bien, V. Palagani, and P. Bozko, "The intestinal microbiota dysbiosis and Clostridium difficile infection: is there a relationship with inflammatory bowel disease?" Therapeutic Advances in Gastroenterology, vol. 6, no. 1, pp. 53-68, 2013.

[42] H. C. Rath, K. H. Wilson, and R. B. Sartor, "Differential induction of colitis and gastritis in HLA-B27 transgenic rats selectively colonized with Bacteroides vulgatus or Escherichia coli," Infection and Immunity, vol. 67, no. 6, pp. 2969-2974, 1999. 
[43] V. Nakano, D. A. Gomes, R. M. E. Arantes, J. R. Nicoli, and M. J. Avila-Campos, "Evaluation of the pathogenicity of the Bacteroides fragilis toxin gene subtypes in gnotobiotic mice," Current Microbiology, vol. 53, no. 2, pp. 113-117, 2006.

[44] J. U. Scher, A. Sczesnak, R. S. Longman et al., "Expansion of intestinal Prevotella copri correlates with enhanced susceptibility to arthritis," eLife, vol. 2013, no. 2, Article ID e01202, 2013.

[45] B. M. Brinkman, A. Becker, R. B. Ayiseh et al., "Gut microbiota affects sensitivity to acute DSS-induced colitis independently of host genotype," Inflammatory Bowel Diseases, vol. 19, no. 12, pp. 2560-2567, 2013.

[46] M. W. J. van Passel, R. Kant, E. G. Zoetendal et al., "The genome of Akkermansia muciniphila, a dedicated intestinal mucin degrader, and its use in exploring intestinal metagenomes," PLoS ONE, vol. 6, no. 3, Article ID e16876, 2011.

[47] M. Derrien, M. C. Collado, K. Ben-Amor, S. Salminen, and W. M. De Vos, "The mucin degrader Akkermansia muciniphila is an abundant resident of the human intestinal tract," Applied and Environmental Microbiology, vol. 74, no. 5, pp. 1646-1648, 2008.

[48] C. Sung Kang, M. Ban, E.-J. Choi et al., "Extracellular vesicles derived from gut microbiota, especially Akkermansia muciniphila, protect the progression of dextran sulfate sodiuminduced colitis," PLoS ONE, vol. 8, no. 10, Article ID e76520, 2013.

[49] C. W. Png, S. K. Lindén, K. S. Gilshenan et al., "Mucolytic bacteria with increased prevalence in IBD mucosa augment in vitro utilization of mucin by other bacteria," The American Journal of Gastroenterology, vol. 105, no. 11, pp. 2420-2428, 2010.

[50] B. P. Ganesh, R. Klopfleisch, G. Loh, and M. Blaut, "Commensal Akkermansia muciniphila exacerbates gut inflammation in Salmonella Typhimurium-infected gnotobiotic mice," PLoS ONE, vol. 8, no. 9, Article ID e74963, 2013.

[51] J. P. Zackular, N. T. Baxter, K. D. Iverson et al., “The gut microbiome modulates colon tumorigenesis," mBio, vol. 4, no. 6, Article ID e00692, 2013.

[52] S. Michail, M. Durbin, D. Turner et al., "Alterations in the gut microbiome of children with severe ulcerative colitis," Inflammatory Bowel Diseases, vol. 18, no. 10, pp. 1799-1808, 2012.

[53] I. Mukhopadhya, R. Hansen, E. M. El-Omar, and G. L. Hold, "IBD—what role do Proteobacteria play?" Nature Reviews Gastroenterology and Hepatology, vol. 9, no. 4, pp. 219-230, 2012. 


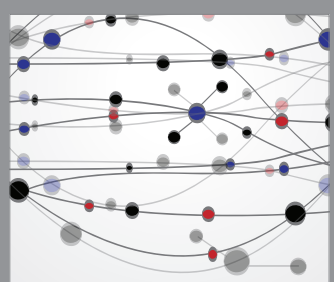

The Scientific World Journal
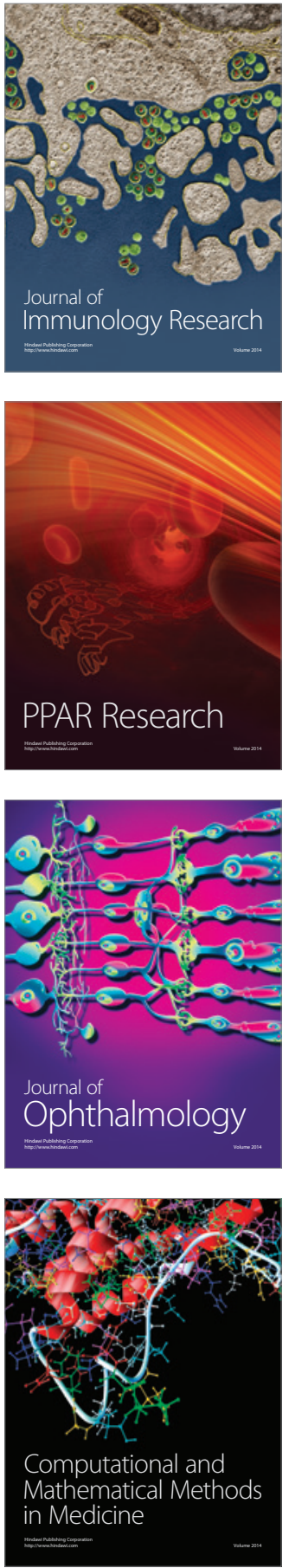

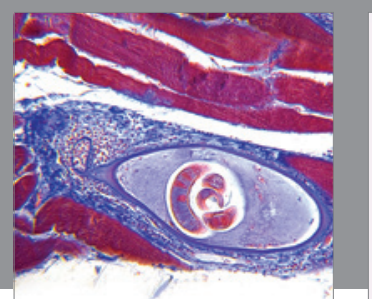

Gastroenterology Research and Practice

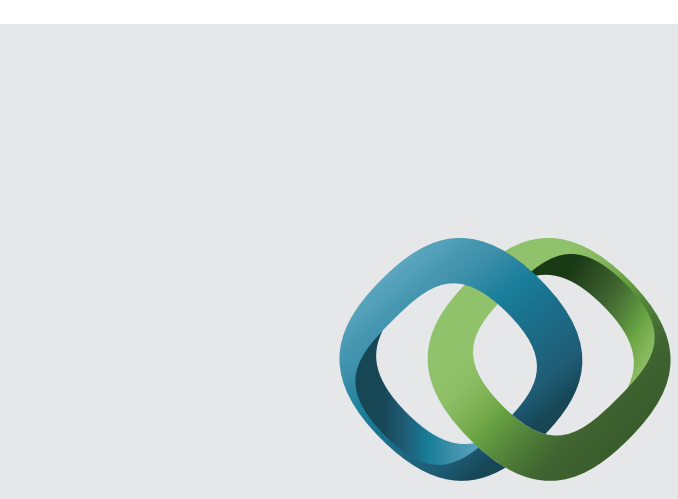

\section{Hindawi}

Submit your manuscripts at

http://www.hindawi.com
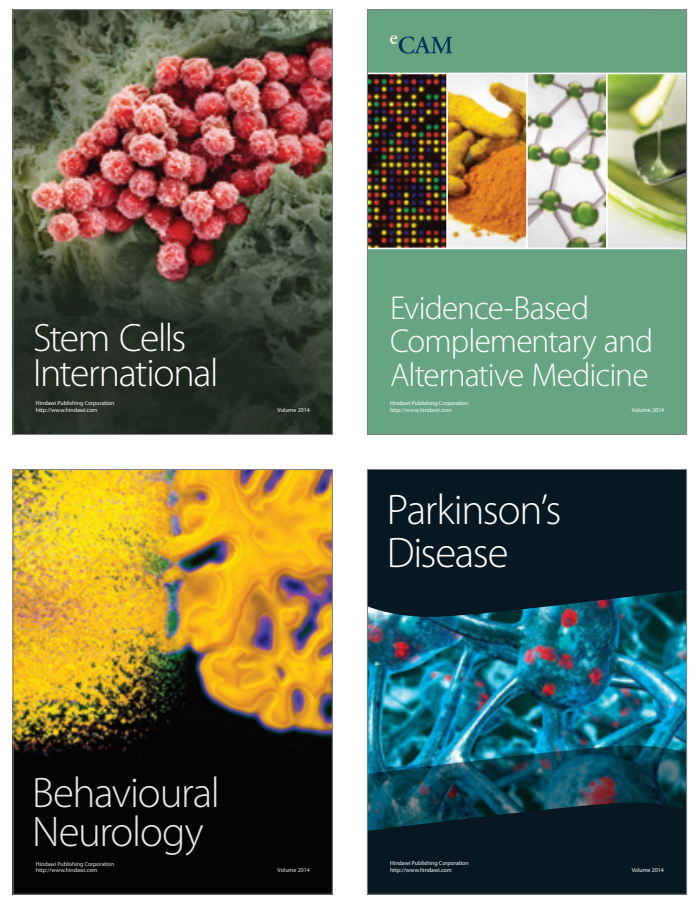
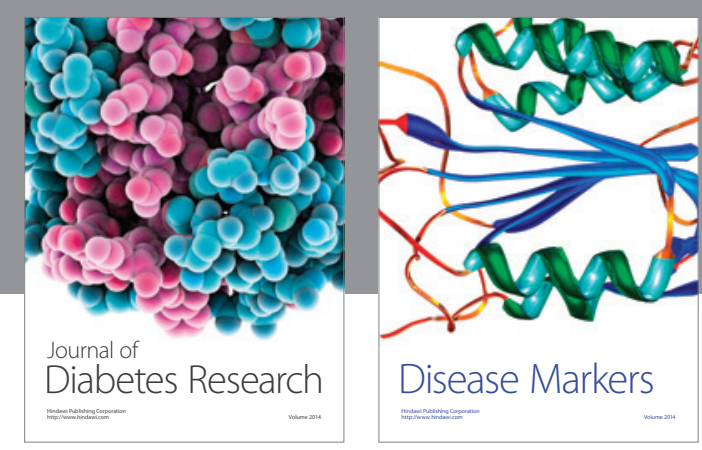

Disease Markers
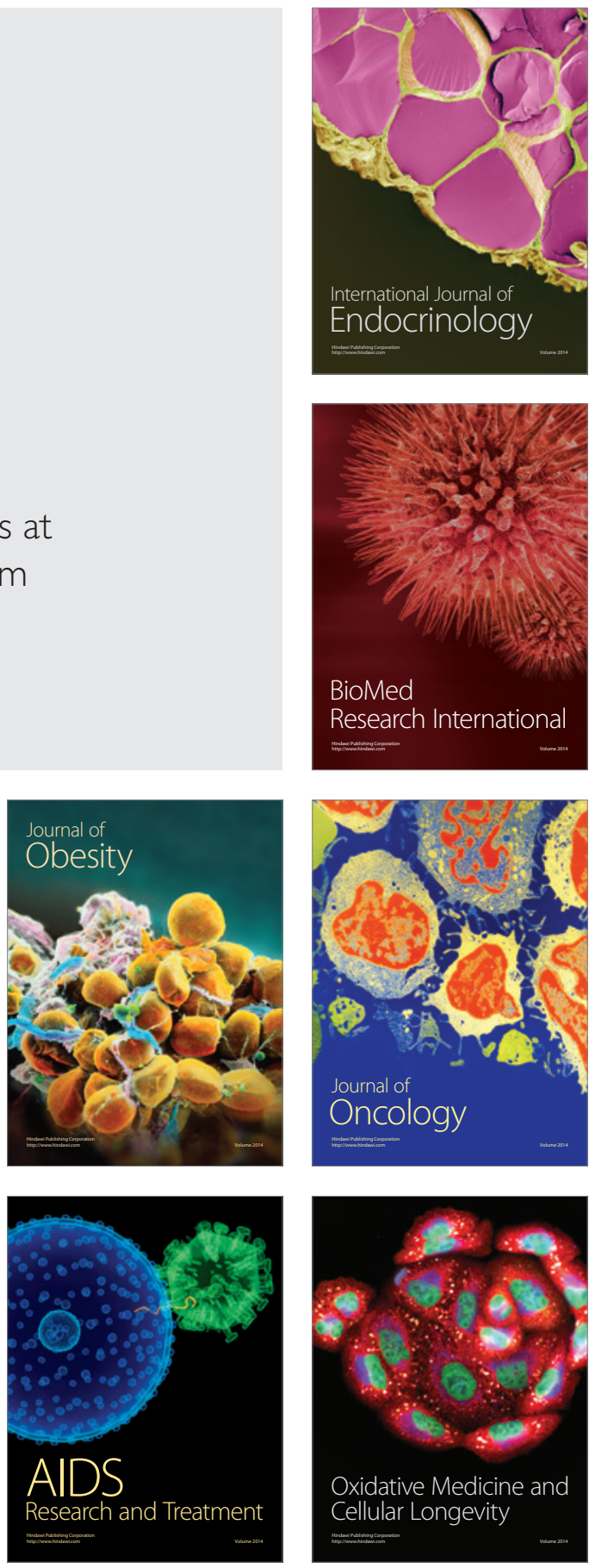